\title{
THE LEGENDARY DRESDEN GREEN DIAMOND
}

\author{
By Robert E. Kane, Shane F. McClure, and Joachim Menzhausen
}

The approximately 41-ct Dresden Green diamond is the largest, and perhaps the finest, green diamond known to have a color of natural origin. A diamond so rich in history is well worth studying for that reason alone, but the Dresden Green offers the unique opportunity of adding valuable data to the quest for means to distinguish natural from laboratory-irradiated green diamonds. In November of 1988, two senior GIA staff members visited the Green Vaults with this goal in mind. The Dresden Green diamond proved to be not only of extraordinary quality but also a very rare type IIa-one of the purest forms of diamond. In addition, the spectral characteristics of this stone were found to overlap those of known treated diamonds. The history, locality origin, and properties of the Dresden Green diamond are discussed in detail in this article.

\section{ABOUT THE AUTHORS}

Mr. Kane is supervisor of identification, and Mr. McClure is senior staff gemologist, at the GIA

Gem Trade Laboratory, Inc., Santa Monica, California. Dr. Menzhausen is director of the Grünes Gewölbe (Green Vaults), Dresden, Germany.

Please see end of article for acknowledgments.

Gems \& Gemology, Vol. 26, No. 4, pp. 248-266

(C) 1991 Gemological Institute of America
$M$ any gemologists dream of being able to examine some of the truly famous gemstones of the world. Unfortunately, few such dreams are realized, since these gems are rarely made available. This was the case for many years with the fabled Dresden Green diamond (figure 1).

Yet just such an opportunity came to pass in late November 1988, when the three authors met in the ancient city of Dresden (figure 2), in what was then East Germany, for the purpose of examining the Dresden Green in the Green Vaults.

Noted jeweler and diamond historian Herbert Tillander was instrumental in making these arrangements. Mr. Tillander is a grandson of the famous Alexander Tillander who founded A. Tillander Jewelers, a well-known firm in St. Petersburg around the turn of the century. The Imperial family of Russia was among their clients. At a conference they had both attended in 1985, Mr. Tillander explained to Mr. Kane that during his research he had had the opportunity to examine many of the diamonds in the Green Vaults. He subsequently made the necessary introductions and inquiries that enabled GIA to negotiate the first complete gemological examination of the Dresden Green diamond. The administrators of the Green Vaults gave their consent to the project in January 1986. As one might expect, the details of such a trip were many and complicated. It was ultimately agreed that the examination should take place November 19-25, 1988, when the museum would be closed for cleaning and the diamond could be removed from its display case. An invitation was subsequently extended to George Bosshart, of the Swiss Foundation for the Research of Gemstones (SSEF), to examine the stone at the same time.

The importance of examining this diamond goes beyond its size and history, to the need to distinguish natural from laboratory-irradiated green diamonds, which is a key concern of GIA and a number of others in the 


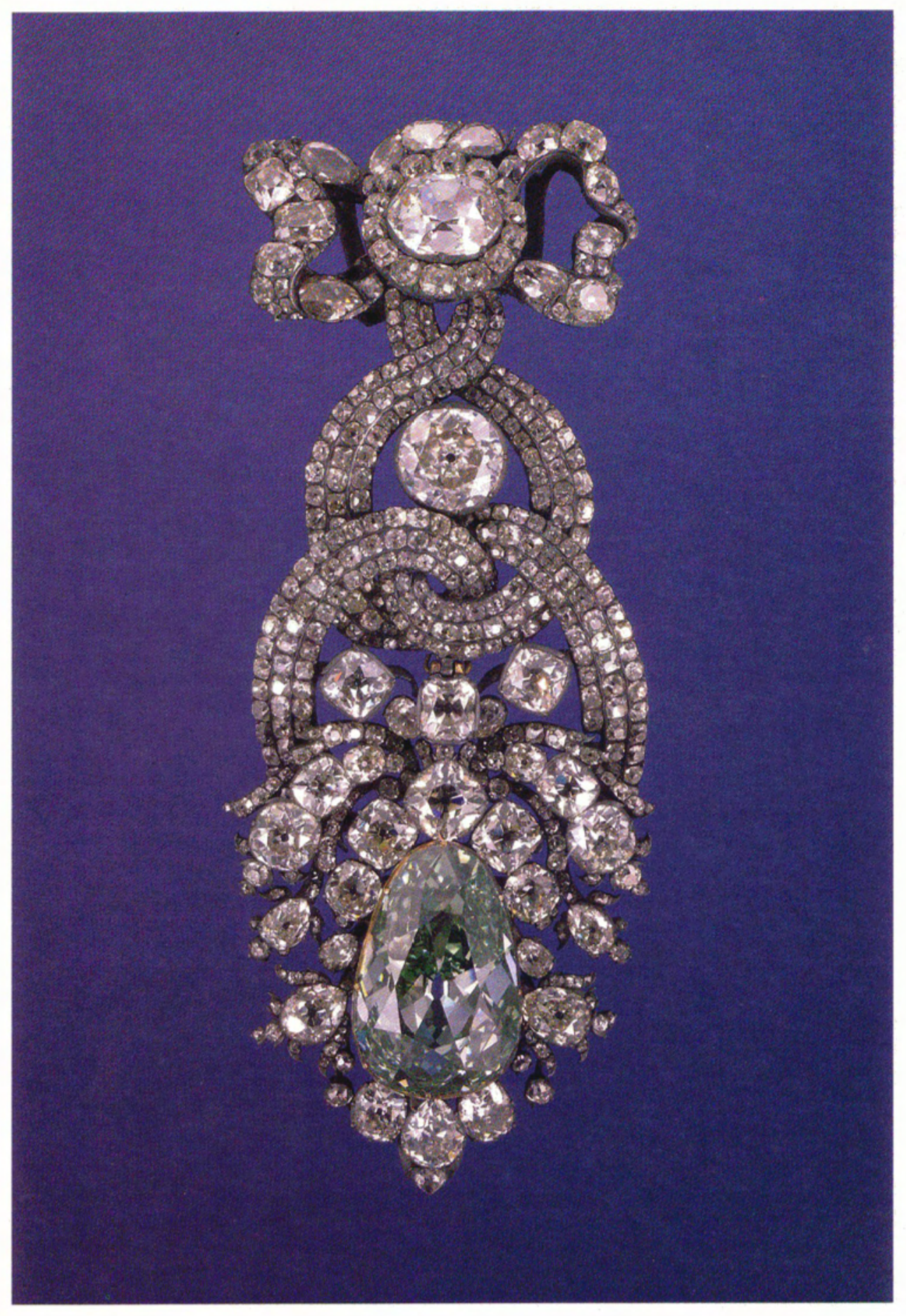

Figure 1. For more than 200 years, the approximately 41-ct Dresden Green diamond has resided in this hat ornament made by Prague jeweler Diessbach in 1768. The flowery bottom portion was originally fashioned by Geneva jeweler André Jacques Pallard in 1746 as a section of a badge of the Order of the Golden Fleece. Photo by Shane F. McClure.

jewelry industry. One of the stumbling blocks of research on this subject is the fact that very few diamonds available for examination possess a green body color that can be proved to be of natural origin. The history of the Dresden Green is documented from 1741 to the present. Its recorded color descriptions over 250 years parallel its present appearance (Inventory Book, 1733; Gruner, 1862;
Streeter, 1882; Erbstein and Erbstein, 1884; Bauer, 1896; Bauer, 1904; Sponsel, 1915; Menzhausen, 1968), which precludes the possibility that the diamond might have been irradiated during its brief tenure in the USSR after World War II. In the authors ${ }^{i}$ opinion, the consistency of these color descriptions with the current appearance of the stone provides overwhelming evidence that this 


\section{A BRIEF HISTORY OF THE GREEN VAULTS}

In 1721, Friedrich Augustus I, elector of Saxony (1694-1733) and king of Poland (1697-1733)better known as Augustus the Strong - gave orders that a certain room of about $90 \mathrm{~m}^{2}$ on the somewhat elevated ground floor of the Dresden Palace should have an opening made in its northern wall to make it accessible from the adjoining hall. This "room" - actually three chambers - was his original treasury.

The three original chambers were designated the "Silver Room," the "Jewellery Room," and the "Hall of Preciosities." Historically in this region, royal and religious treasuries alike had been closed repositories, well guarded and secured (Menzhausen, 1968). By opening these rooms to more general access, Augustus the Strong announced his intention to have his treasury represent a new kind of collection: a museum.

The walls had originally been painted green, a fact discovered recently when portions added in the $18 \mathrm{th}$-century were taken down for restoration. There is also reference by Augustus the Strong in 1727 to rooms with vaulted ceilings in this general area that were used to house his collection. The descriptive name Green Vaults (Grünes Gewölbe) had very probably been used colloquially by the inhabitants of the palace ever since this part of the building was completed in 1554; the name appears for the first time in a document written in 1572 . Today, Green Vaults is the name given to the rooms that house the collections in what is now known as the Albertinum, the museum that occupies the structure that used to be the Dresden Palace. The Green Vaults still contain artifacts and works of art from the original collection of Augustus the Strong (Menzhausen, 1968).

In 1942, during the upheaval of World War II, the collections of the Green Vaults were packed into crates and removed to nearby Königstein Fortress, where they had been deposited twice before, during the Seven Years' War (1756-1763) and the "Wars of Liberation" (1813). With the end of World War II, in 1945, former French prisoners of war held at Königstein took command of the fortress. They protected the collection until a detachment from the Soviet army that was specially commissioned to safeguard works of art arrived to take it to Moscow (Menzhausen, 1968).

Although most of the original Dresden Palace was destroyed during the war, along with the entire center of Dresden, two of the original three rooms of the Green Vaults remained almost intact. There was considerable damage, however, to the Jewellery Room (figure 3). In addition, the special library of the collection was destroyed by fire, including all the card indexes and records, as well as several files concerning the history of the Green Vaults. Hundreds of descriptive reports were also lost, together with the drawings made by the 18thcentury court jewelers. Only the inventory books were saved, thanks to the care and energy of Dr. Erna von Watzdorf, one of the scholars then working in the Historical Museum, who had them taken to a repository outside of Dresden. They now form the basis for all new work on the Green Vaults. The collection of the Green Vaults was returned to the German people by the Soviet government in 1958 (Menzhausen, 1968). The collection is now on display in the contemporary surroundings of the Albertinum (figure 4).

\section{HISTORY OF . \\ THE DRESDEN \\ GREEN DIAMOND}

The Dresden Green diamond has had a fascinating and complex history. In researching this history, we used a variety of sources, including archives in Dresden, London, Idar-Oberstein, and the United States. The known chronology of the Dresden

Figure 4. The collections of the Green Vaults are now housed in a contemporary museum, the Albertinum, built on the site of the original Dresden Palace. The lewellery Room is at the far end of this photo. Photo by Shane F. McClure.

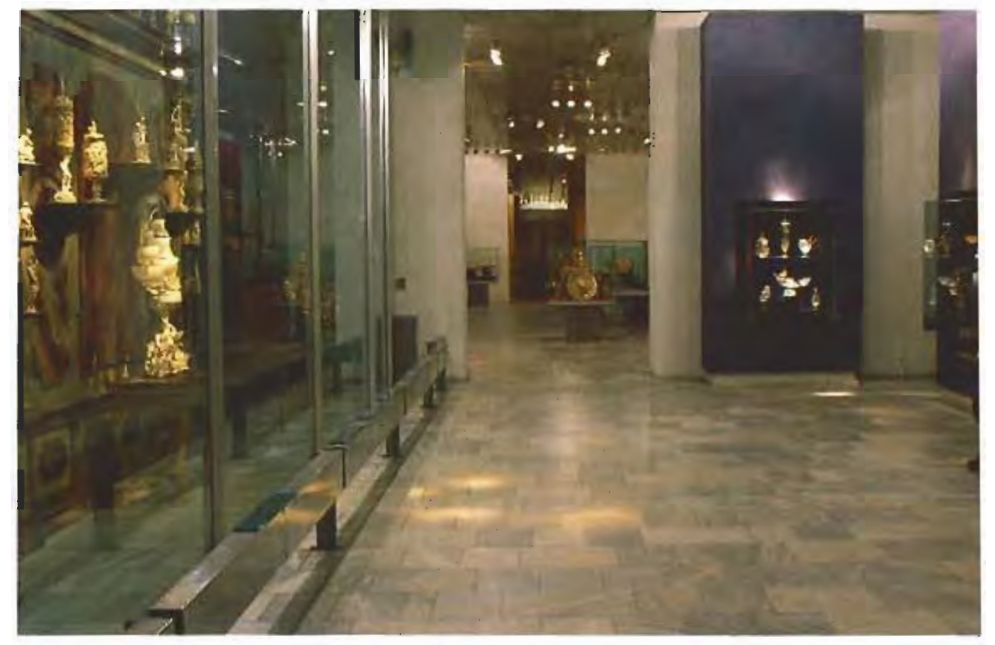




\section{Chronological History of the Dresden Green Diamond. *}

During The large green diamond is brought (presumably to or prior London) from the Golconda district of India by to 1726 Marcus Moses.

1726 The green diamond (possibly in the rough) is offered for sale out of London in 1726 to Friedrich Augustus I ("Augustus the Strong"), elector of Saxony and king of Poland. The asking price is $£ 30,000$

1741 The green diamond is sold to Friedrich Augustus II at the Great Anmual Easter Fair at Leipzig by a Jewish merchant named Delles. The price has been quoted alternately as 60,000 , 200,000 , or 400,000 thaler.

1742 Court Jeweler Johann Friedrich Dinglinger is commissioned by Friedrich Augustus II to fashion a badge of the Order of the Golden Fleece to hold the Dresden Green.

1746 Dinglinger's Golden Fleece is broken up and another is created by Genoan master goldsmith André Jacques Pallard. Also set in this Fleece is the approximately 49-ct Saxon white diamond.

1753 The British Museum in London receives a model of the Dresden Green diamond that was probābly made when the stone was cut.

1756-63 The green diamond and the contents of the Green Vaults are moved to Königstein Fortress for safekeeping during the Seven Years War.

1768 After Saxony's defeat in the Seven Years War, Pallard's Fleece is dismantled by a jeweler named Diessbach from Prague. The section holding the Dresden Green is kept intact and is made part of the hat ornament in which it curently resides. The section holding the Saxon white also remains intact and is made part of a shoulder knot that also exists today.

1813? During the Wars of Liberation, the green diamond and the contents of the Green Vaults are again safely stored in the old Königstein Fortress.

1925 Professor Rösch and Dr. Krümbhaar, of Germany, photograph and examine the green diamond in great detail with an optical goniometer.

1942 During World War II, the entire collection of the Green Vaults is again stored in the vaults of the Königstein Fortress.

1945 At the close of World War II, a Russian organization called the Soviet Trophies Commission removes the collection, including the Dresden Green diamond, from Königstein and takes the items to Russia.

1958 The contents of the Green Vaults are returned to Dresden.

*See text for corresponding references.

Green diamond is summarized in the accompanying box and discussed below.

The first reference to the presence of the green diamond in Dresden is in inventory book no. 16 of the Green Vaults (figure 5). The entry for the Dresden Green reports that in 1741 a merchant
1959 A major exhibition at the Albertinum in Dresden features items from the Green Vaults and other collections. The Dresden Green diamond is placed on public display for the first time since 1942.

1974 The Green Vaults are reopened and a representative selection of the jewelry collection is placed on display.

1988 The first complete gemological examination of the Dresden Green diamond. named Delles sold it to the son of Augustus the Strong, Friedrich Augustus II, elector of Saxony and (as Augustus III) king of Poland (17331763).

Little is known about the diamond before 1741. It was mentioned in a 1726 letter from Baron 


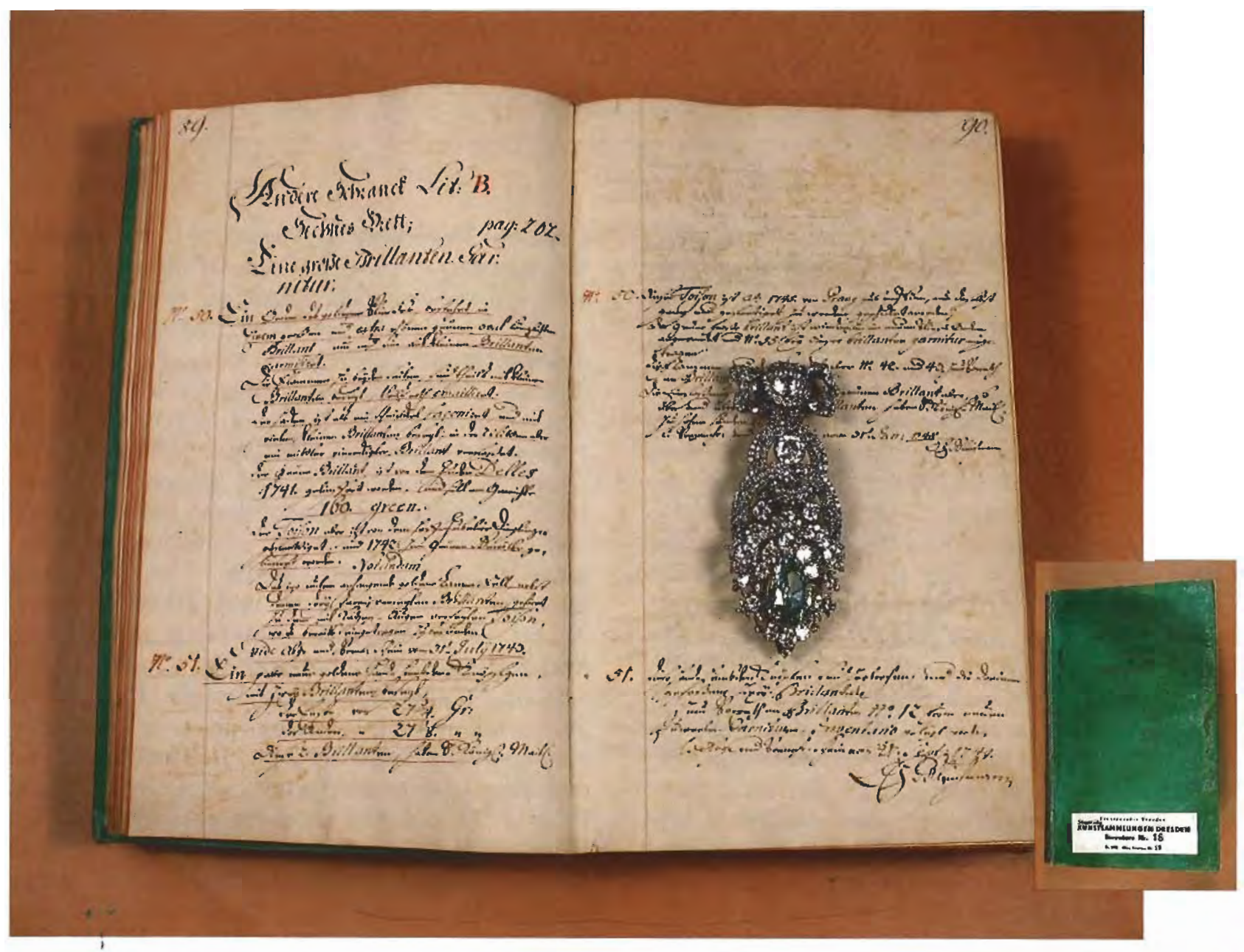

\section{[page 89] Second Drawer Lit: $B$ Sixth Shelf Folio: 202 \\ $\mathscr{A}$ Large 'Diamond Set}

No. so. An order of the Golden 'Fleece consists of an extraordinarily beauliful green oval sfiaped diamond surrounded by small diamonds. The flames on both sides are partly sel with small diamonds, parily enameled wilh red.

The fook is fasfioned as a scroll and set with many small diamonds. In the middle is a medium sized rectangular dianond.

The green dinnond was supplied in 1741 by the Jew 'Delles and fias a weight of 160 green." "The Golden "Flece was mate by the Count Jeweler Dinglinger and delinered in 1742 to the Green Vault.

\section{Note}

The golden Lambskin fanging below, with the three diamonds transferred to il, belong to the Golden 'Fleece with the cat's eyes as recorded. See certificale daled Iuly 31,1743 .
No. 5o. This flece was sent in about 7745 via - Prague to Viema for redesigning. 'The large green diamond was used ligain in the new Order of the Golden 'Flece and recorded as No. 55 in this diamond set. The flames and scroll were stored in the stock of diamonds; numbers 42 and 43 . The setting of the small dianonds around the green diamond, flowever, remained in the hands of his Majesty.

This certification is signed by the officiul guordian on Jamuary 1748

'Bleichinamn

"From the English word "grain"; 160 grains equals approximately 40 Lipish carats.

Figure 5. The hat ornament containing the Dresden Green diamond is seen here displayed on the original inventory book no. 16 of the Green Vaults. The book is open to entry No. 50, in which the acquisition of the green diamond is recorded. A translation of this entry is given below. It is interesting to note that the cover of the book is green (see inset). Photos by Shane F. McClure. 
Gautier, "assessor" at the "Geheimes Rath's Collegium" in Dresden, to Le Coq, then Polish ambassador to London. The letter spoke of the green diamond being offered to Augustus the Strong by a merchant from London for the sum of 30,000 pounds sterling (Boutan, 1886).

The only other reference to the existence of the green diamond before 1941 that the authors were able to locate was encountered in a book by respected mineralogist C. J. Spencer (1971). Spencer makes reference to a model of the Dresden Green diamond that was part of the massive collection of Sir Hans Sloane, which was acquired by the British Museum of Natural History in 1753. On checking with the museum, we discovered that they did indeed have such a model (figure 6). In fact, they have two. The registry index cards /registry no. $85438 \mathrm{~A}$ and $\mathrm{B}$ ) for these models state that one of them is probably from Sloane. An entry that appears to be from Sloane's own catalog of his collection is quoted on the registry card: "A modell of the green diamond brought from the diamond mines in Golconda by Marcus Moses valued at 20000 1s." This remarkable record, of which we could find no previous report in the literature, both establishes a firm link between the green diamond and India, and names the man who first brought the rough to the West. We could find no further mention of Marcus Moses in the course of our research. Because it is unlikely that a private collector could have acquired a model of the

Figure 6. This glass model of the Dresden Green diamond was acquired by the British Museum of Natural History in 1753. Courtesy of the British Museum; photo by Shane F. McClure.

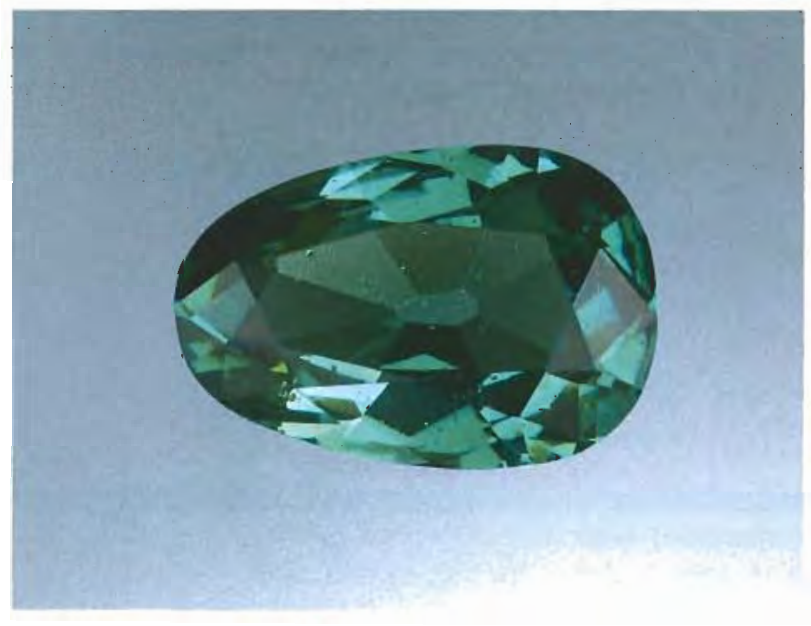

Dresden Green after the stone was in the hands of Saxon royalty, the logical source of the model is the cutter of the diamond, sometime before 1741 .

Friedrich Augustus II purchased the green diamond at the Great Annual Easter Fair at Leipzig (Boutan, 1886). The merchant, Delles, has been alternately described as Jewish (Green Vaults inventory book no. 16), Armenian (Boutan, 1886), Dutch (Copeland, 1974), and English (Watzdorf, 1962). The purchase price of the Dresden Green is also a matter of controversy in the literature. The most frequently quoted figure is 200,000 thaler (Streeter, 1882; Erbstein and Erbstein, 1884; Führer, 1918; Watzdorf, 1962; Holzhausen, 1966; Menzhausen, 1968; Balfour, 1987), while other references list 60,000 thaler /Cattelle, 1911; Bauer, 1932). The most interesting reference we uncovered quotes still another price. It is mentioned in a collection of letters of Frederick the Great, king of Prussia (1712-1786), that was compiled by Max Hein (1914). The quote states that "For the siege of Brün the King of Poland was asked for heavy artillery. He refused due to the scarcity of money; he had just spent 400,000 thaler for a large green diamond."

In 1742, Friedrich Augustus II ordered Court Jeweler Johann Friedrich Dinglinger to set the green diamond in a badge of the Order of the Golden Fleece. This order was founded in 1429 by Phillip the Good to encourage and reward virtue and faith among men of high lineage (Tillander, 1988). The original Golden Fleece only survived four years. For reasons unknown, Dinglinger's badge was broken up in 1746. Friedrich Augustus II then commissioned Geneva goldsmith André Jacques Pallard (who was then living in Vienna) to fashion another Golden Fleece featuring the Dresden Green together with the largest diamond in the Green Vaults collection, the Saxon White /which has alternately been described as weighing $48.50 \mathrm{ct}$ [Menzhausen, 1968] and 49.71 ct [Gaal, 1977]). These two stones reportedly remained in this setting for more than 20 years (Menzhausen, 1968). The rendering of this piece shown in figure 7 is based on a reconstruction suggested by Tillander (1988).

From 1756 to 1763 , the contents of the Green Vaults were stored at the Königstein Fortress to protect them against the ravages of the Seven Years' War. Several years after the close of this war (in which Saxony was defeated), Pallard's Fleece was also dismantled. In 1768, a jeweler named 
Diessbach from Austrian Prague was commissioned to dismantle the badge and use two of the main sections to fashion a shoulder knot and a hat ornament, both of which exist today (Menzhausen, 1968).

The Dresden Green now resides in Diessbach's hat ornament (figure 1). The bottom portion of the omament that contains the green diamond is actually an intact section of the Golden Fleece made by Pallard (Menzhausen, 1968). From the back (figure 8), one can still see a loop on the bottom of the piece that once connected it to the flames of the Golden Fleece. Above this section Diessbach added a ribbon-like design set with rows of small old-mine-cut diamonds that sweeps up from the sides and culminates in a bow. The bow is set with somewhat large antique-brilliant-cut diamonds. In addition, two large antique-cut brilliants were added, one in the center of the bow and another directly below it in the middle of the ribbons. On the back of the bow are two large loops that allowed the hat ornament to be attached by a ribbon or hat band.

The green diamond remained in the Green Vaults for the next several decades, until the early 19th century, when the Wars of Liberation forced the contents of the Green Vaults to once again be moved to Königstein Fortress.

In 1925, Prof. S. Rösch (a German mineralogist) and Dr. W. Krümbhaar (former director of the Dusseldorf Laboratory for Diamond Research) were allowed to examine the Dresden Green in great detail with an optical goniometer. This enabled them to measure exact facet angles within the limits of the bezel that still held the diamond (Rösch and Krümbhaar, 1926; Rösch, 1957).

In 1942, the treasures of the Green Vaults were once again moved to Königstein Fortress for safekeeping. At the close of World War II, a Russian organization called the Soviet Trophies Commission took the contents of the Green Vaults to Moscow; they were returned to Dresden in 1958.

The Dresden Green and its hat ornament are now on display in the Green Vaults as part of a jewelry set referred to as the "Brilliant Garnitur" (figure 9).

\section{THE COUNTRY OF ORIGIN DEBATE: INDIA OR BRAZIL?}

Tillander (1988) states that "without doubt the rough diamond [from which the famed 41-ct Dresden Green was cut] is of Indian origin even though

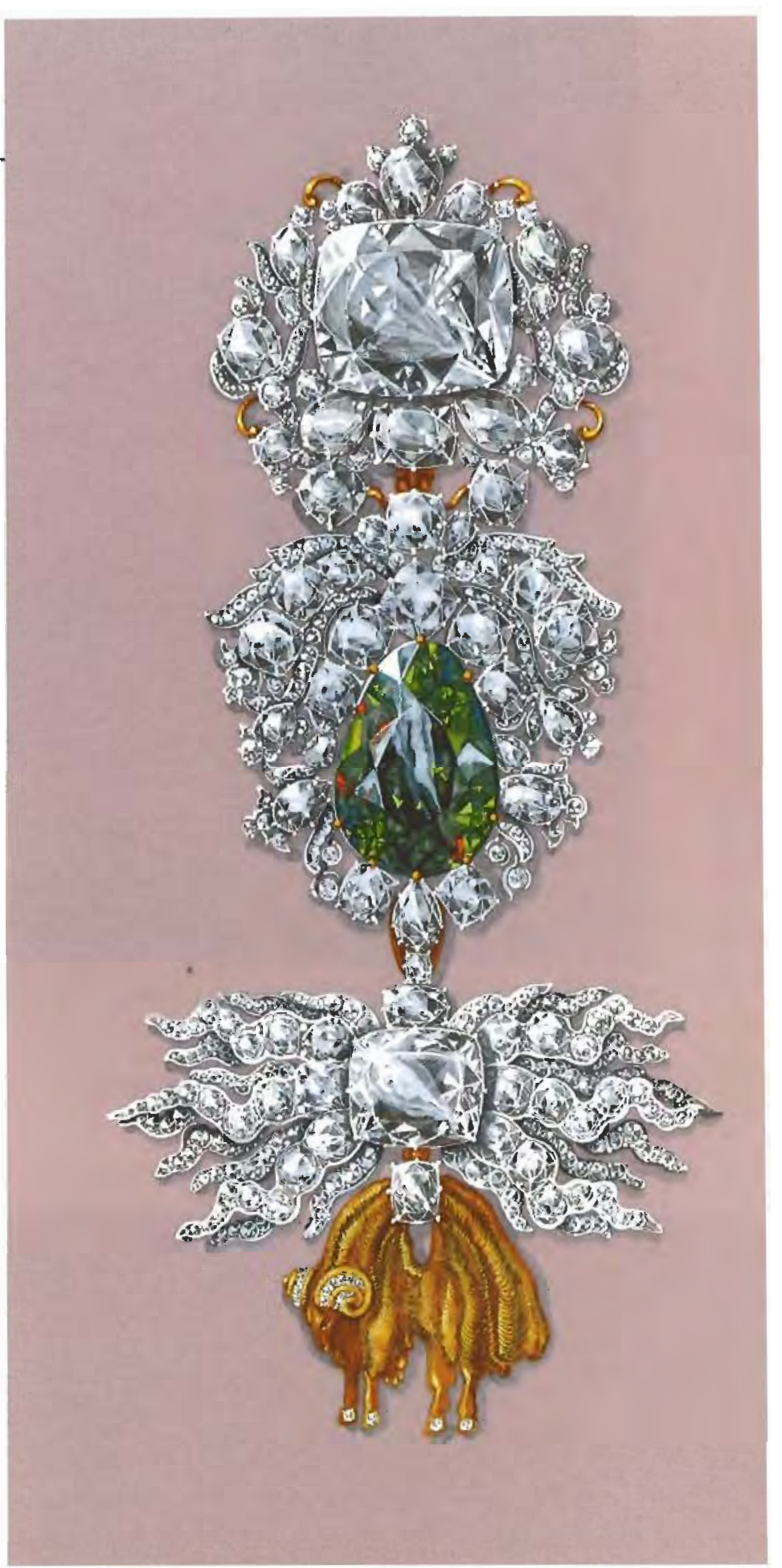

Figure 7. This rendering of a badge of the Order of the Golden Fleece reportedly manufactured by pallard in 1746 is a theoretical reconstruction based on a suggestion by Tillander (1988). The top section holding the approximately 49-ct Saxon White diamond and the center section holding the Dresden Green diamond still exist today in a shoulder knot and a hat ornament, respectively. The flames and fleece on the bottom of the piece are based on written descriptions and existing examples of Pallard's work. Rendering by Judy Evans, Krementz Gemstones; (C) Robert E. Kane. 


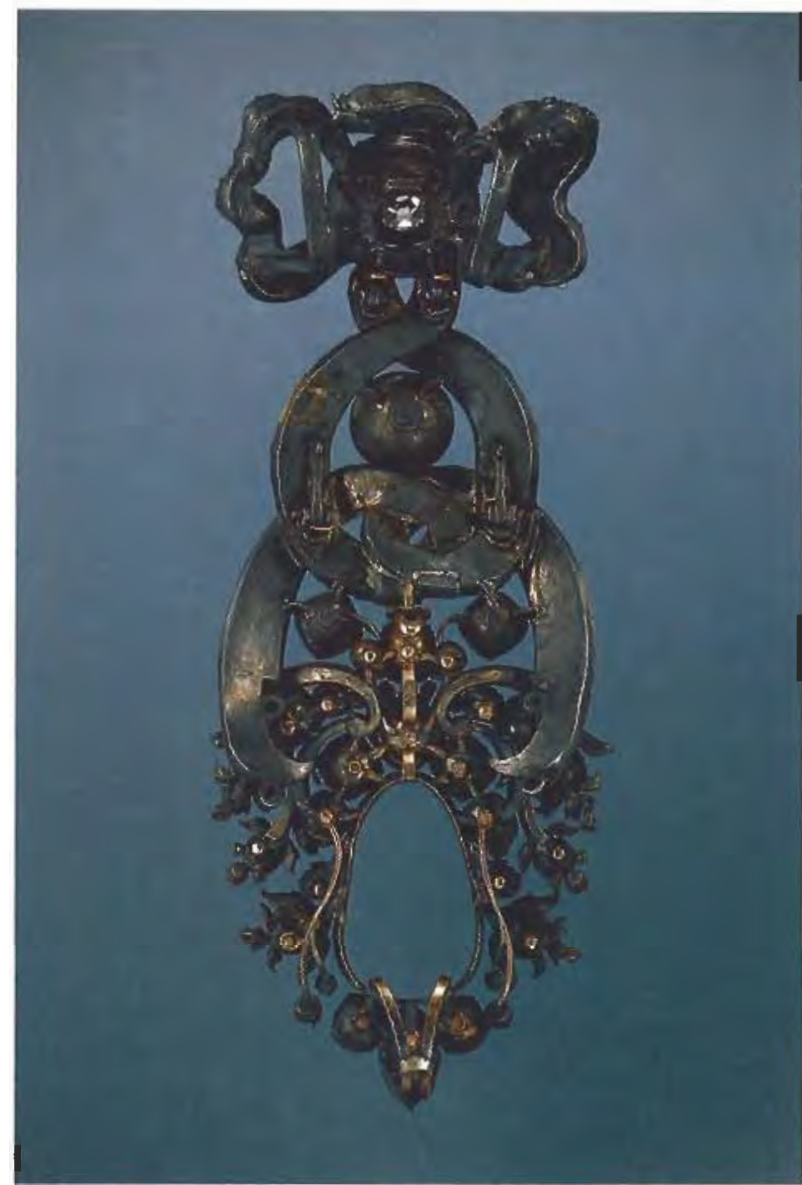

Figure 8. The back side of the Dresden Green hat ornament clearly shows, on the bottom of the piece, the loop that is a remnant of the Golden Fleece manufactured in 1746. Photo by Shane F. McClure.

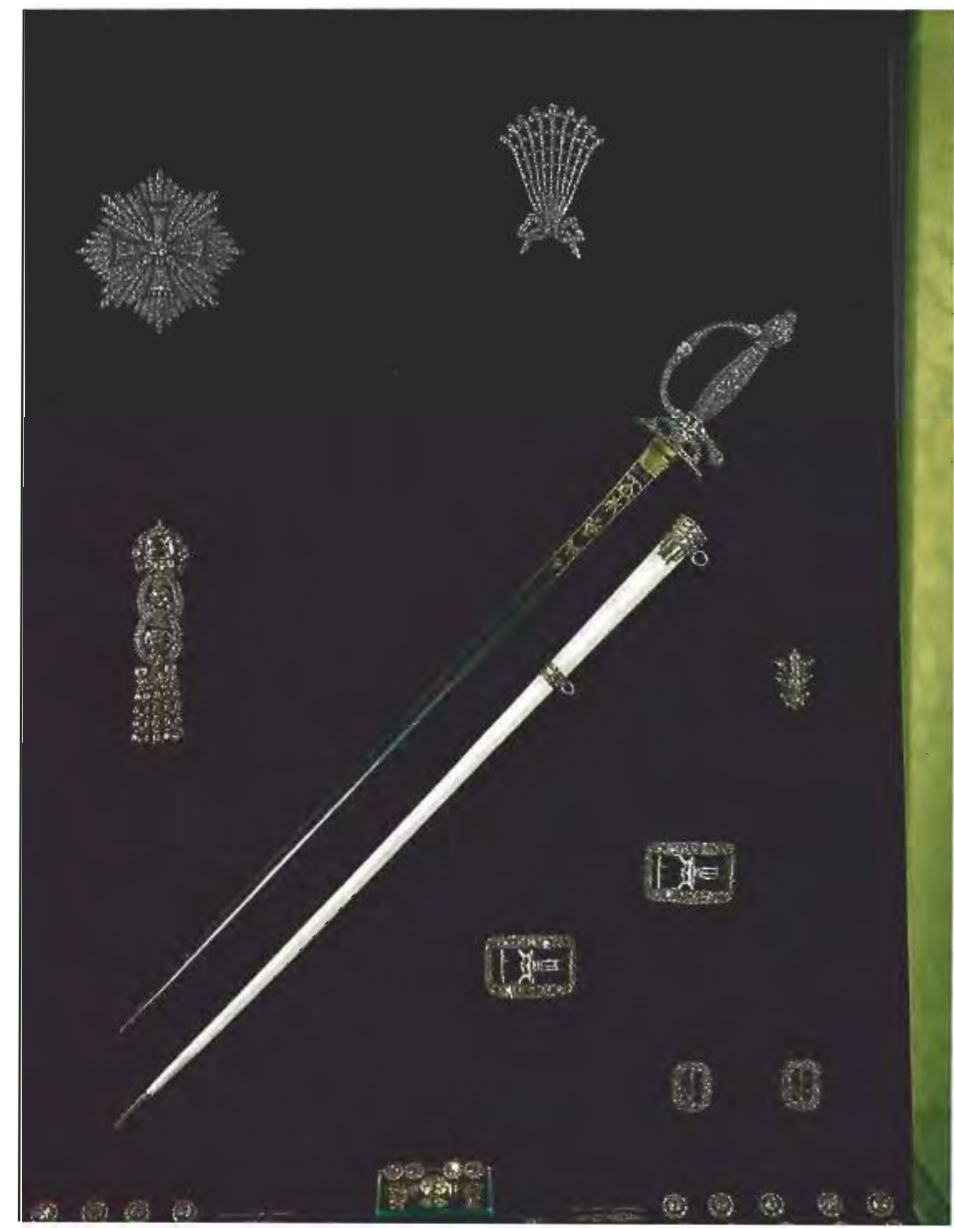

in a few publications Brazil has been suggested." The latter suggestion probably results from reports in the literature of a colorless diamond from Brazil of similar shape (but larger, $76 \mathrm{ct}$ ) owned by a Mr. E. Dresden (see, e.g., Reis, 1959). This stone was also referred to as the English Dresden (Streeter, 1882).

Tillander's statement receives further support from the registry card to the Sloane Collection model of the diamond that was discussed above. The description that accompanied the model stated that the original stone was of Golconda (India) origin.

\section{THE DRESDEN GREEN: PHYSICAL APPEARANCE}

We began our examination of the Dresden Green with a thorough evaluation of its physical appearance and characteristics. These included the shape and cut, estimated carat weight, proportions, finish, clarity, and color (see table 1).

Shape and Cut. The Dresden Green diamond is a modified pear-shaped brilliant cut. It has the general facet shape, small table, and large culet that are commonly associated with the old-mine and old-European styles of cutting. The attractive overall shape of this stone has been referred to as a "pendeloque" (Boutan, 1886; Balfour, 1987).

Although the Dresden Green is securely set in a gold bezel with eight prongs, we used a screw micrometer in conjunction with a gemological microscope to obtain what we believe are accurate measurements of the stone: $29.75 \mathrm{~mm}$ long $\times$ $19.88 \mathrm{~mm}$ wide $\times 10.29 \mathrm{~mm}$ deep.

Carat Weight. Because the famous green diamond could not be removed from the bezel-prong mounting without risk of damage to the historic metalwork, we could not obtain an accurate weight with

Figure 9. Today, the hat ornament that holds the Dresden Green is displayed as part of this set of jewelry known as the "Brilliant Garnitur." The hat ornament had been removed for our examination at the time this photo was taken; a disturbance in the open area of velvet above the sword indicates where it was mounted. This set of jewelry also contains the Saxon White diamond (approximately $49 \mathrm{ct}$ ), set in the shoulder knot on the left, and the Dresden Yellow diamond $(38 \mathrm{ct}$ ), one of the unmounted yellow diamonds at the bottom center. Photo by Shane F. McClure. 
TABLE 1. Gemological description of the Dresden Green diamond.

\begin{tabular}{|c|c|}
\hline $\begin{array}{l}\text { SHAPE AND CUT ... } \\
\text { Measurements .... } \\
\text { Weight } \ldots . . . . .\end{array}$ & $\begin{array}{l}\text { MODIFIED PEAR-SHAPED BRILLIANTa } \\
29.75 \times 19.88 \times 10.29 \mathrm{MM} \\
41 \text { CARATS }\end{array}$ \\
\hline \multicolumn{2}{|l|}{ PROPORTIONS } \\
\hline Depth....... & $51.8 \%$ \\
\hline Table... & $51 \%$ \\
\hline Girdle ....... & EXTREMELY THIN TO VERY THING \\
\hline Culet. . . . . . . . & SLIGHTLY LARGE \\
\hline FINISH & \\
\hline Polish .... & VERY GOOD \\
\hline Symmetry & GOOD \\
\hline CLARITY. & $V_{S_{1}}$ (VERY SLIGHTLY INCLUDED)d \\
\hline \multicolumn{2}{|l|}{ COLORe } \\
\hline Hue.. & GREEN \\
\hline Tone ....... & MEDIUM (5) \\
\hline Saturation . & SLIGHTLY GRAYISH (1.5) \\
\hline Fluorescence & Nonef \\
\hline
\end{tabular}

aFacet shape and size are consistent with the antique style of culting commonly associated with old-mine and old-European cuts. ${ }^{D}$ As reported by J. Menzhausen (1986).

cNearly the entire area of the girdle is covered with nicks and chips, with a very few bruted areas.

oThe nature and location of the inclusions and surface blemishes that could be seen (given the presence of the bezel) suggest that if this diamond were properly recut it could possibly receive an internally flawless or even a flawless grade. We are not, however, suggesting that such an important historical diamond ever be recut. eIn accordance with GIA Colored Stone Grading System nomenclature. when expesed to a GIA Gem Instruments 4-wall combination short-wave $(254.6 \mathrm{~nm}) / / \mathrm{long}$-wave $(366 \mathrm{~nm})$ ultraviolet radiation lamp.

a modern electronic balance. However, we were able to establish an estimated weight. On the basis of extensive archival research, we concluded that the last time the diamond was weighed was before it was set in its present "bezel" mounting in 1742. The original 1741 handwritten entry in the no. 16 inventory book of the Green Vaults (again, see figure 5) states that the green diamond "has a weight of 160 green [sic]." This is in reference to the English word "grain." Based on numerous calculations made by Streeter (1882), there are four grains in an antique carat. This would equate to a weight of 40 antique carats for the Dresden Green. The carat as a unit of measure was not standardized until the metric carat $(200 \mathrm{mg}$ ) was accepted in the beginning of the 20th century. Before then, its value depended on the city or country in which it was being used. In Leipzig, where the Dresden was purchased, one carat was equal to $205 \mathrm{mg}$ (Lenzen, 1970). Thus we arrive at the generally accepted weight of 41 metric carats for the Dresden Green (Menzhausen, 1968, 1986). Prof. Rösch and Dr. Krümbhaar (1926) arrived at approximately the same weight on the basis of the calculations they made during their 1925 examination of the stone.
Proportions. As discussed above, in 1925 Rösch and Krümbhaar used an optical goniometer to measure the angles of inclination of all the completely accessible facets outside the bezel mounting (Rösch, 1957; see table 2). Tillander (1988) also studied the cutting and proportions of this diamond. Table 3 shows the present authors' analyses of the Dresden Green's proportions.

The depth percentage of a pear shape is its depth (table to culet) expressed as a percentage of its maximum width (perpendicular to its length) at the girdle. This value is calculated by simply dividing the actual depth by the width. The depth percentage of the Dresden Green diamond is 51.8\%.

The accepted method of expressing the table percentage of fancy-cut diamonds is first to measure the width at the center of the table, point to point, in millimeters. This measurement for the Dresden Green was $10.15 \mathrm{~mm}$. This value is then divided by the largest width (at the girdle), which was 19.88 $\mathrm{mm}$. The table percentage for the Dresden Green diamond was calculated to be $51 \%$.

Because of its unique bezel-prong setting, about $20 \%$ of the girdle was completely obscured from view. The areas that were visible ranged from extremely thin to very thin, and were marked by 
TABLE 2. Data and illustrations from Professor Rösch and Dr. Krümbhaar's 1925 detailed examinations of the Dresden Green diamond, including precise facet angle measurements obtained using an optical goniometer (Rösch and Krümbhaar, 1926; Rösch, 1957).

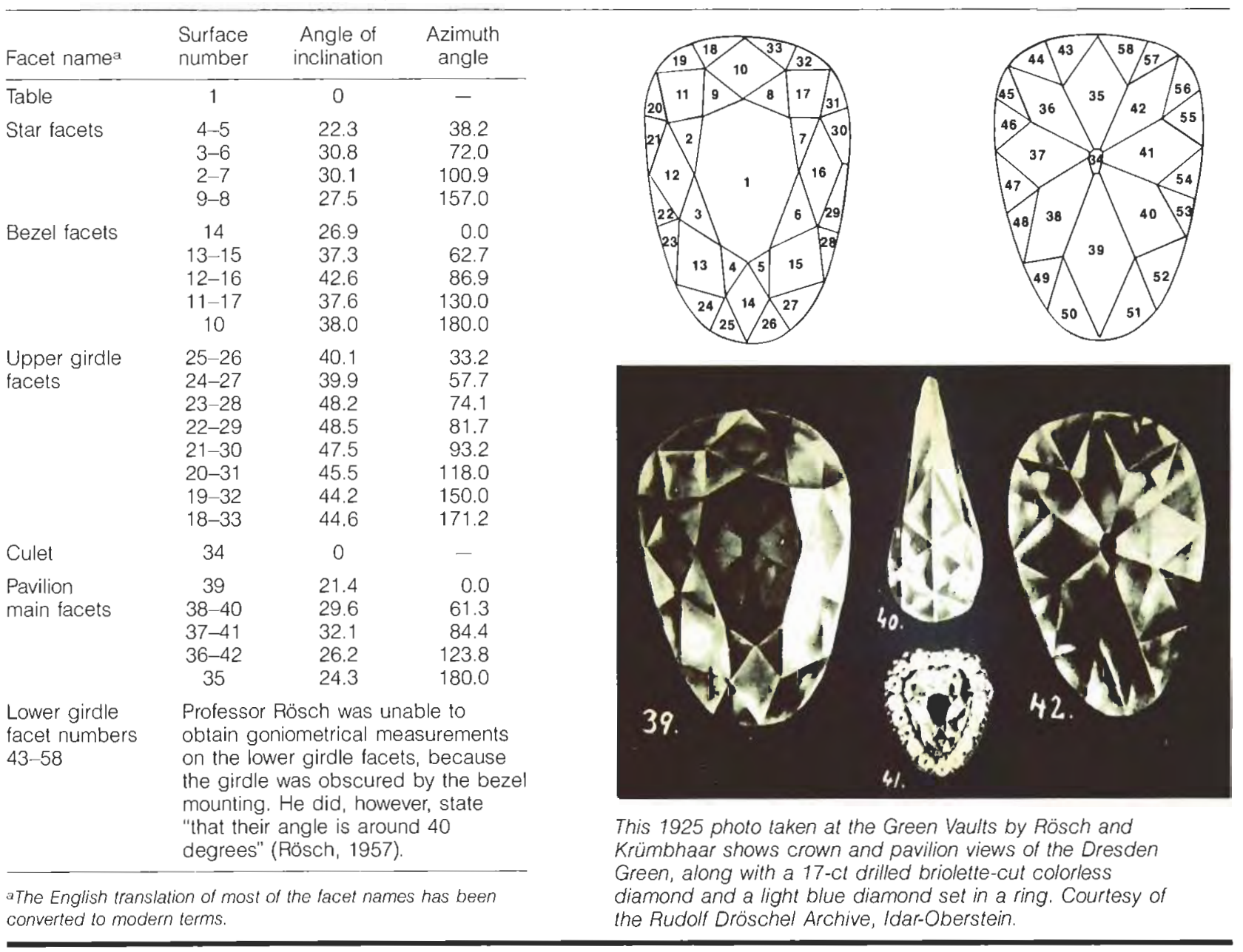

numerous nicks, abrasions, and small chips. The girdle was slightly wavy.

The culet, an elongated heptagon, measured 3.25 $\mathrm{mm} \times 1.65 \mathrm{~mm}$. In GIA diamond-grading terms, the culet of the Dresden Green would be called slightly large.

Finish. We were very impressed with the quality of the finish. It seemed remarkable that a diamond cut prior to 1741 would have a polish of sufficient quality to deserve a "very good" grade by today's rigid diamond-grading standards. The symmetry was "good," displaying only very minor pointing and alignment faults, a slightly wavy girdle, and several extra facets on the pavilion at the girdle.

Clarity. One is immediately impressed by the exceptional transparency of the Dresden Green. In spite of the considerable thickness of the diamond, objects viewed through it could be seen very clearly. While the superior polish on the stone certainly contributes to this, the diamond itself has an apparent transparency that is, in the experience of the authors, very rare. It is reminiscent of that observed in colorless diamonds from the ancient Golconda mining district of India, which are also frequently large (see Krashes, 1988, for illustrations and descriptions of famous Golconda diamonds once sold by Harry Winston). Diamonds from the Golconda district are legendary throughout the diamond trade for their exceptional transparency, which is rarely equaled in diamonds from other localities (Bauer, 1896; Bauer, 1904; Gaal, 1977; R. Crowningshield, pers. comm., 1990). Although the assessment of transparency is unavoidably subjective, the remarkable transparency of a "Golconda-type" diamond is not soon forgotten. 
TABLE 3. Proportions of the Dresden Green diamond.

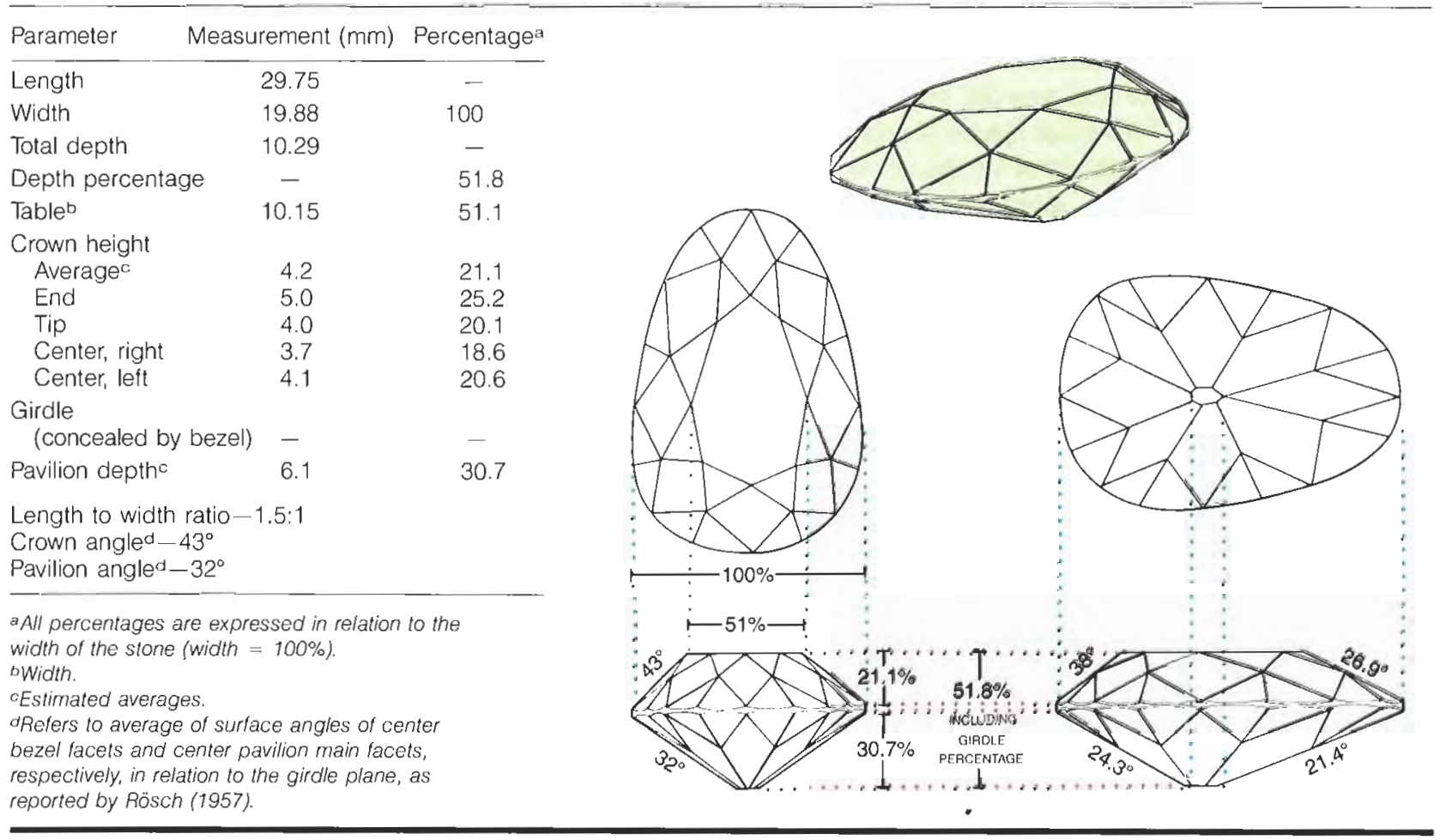

reported by Rosch (1957).

We determined the clarity of the green diamond to be $\mathrm{VS}_{1}$. As the plotting diagram in figure 10 shows, all of the chips and small feathers are near the girdle and all are fairly shallow. The only completely internal inclusion is a tiny opaque brown crystal (approximately $0.1 \mathrm{~mm} \times 0.05 \mathrm{~mm}$ ) that is plotted under a bezel facet. We estimated the crystal to be located approximately $0.15 \mathrm{~mm}$ from the nearest surface of the pavilion. Even with high magnification (near $120 \times$ ), we could not identify a clear crystal habit for this inclusion. It appeared to be an aggregate composed of minute, slender, pointed crystals.

Over the course of two-and-a-half centuries, the Dresden Green diamond has suffered only very slight abrasion damage on some of the facet junctions, primarily around the edge of the table. A few minute abrasions are present on other crown facet junctions, as well as on the junctions in the vicinity of the culet. Even the most prominent of these abrasions are not easily visible with the unaided eye. There is also one small scratch on the table, as shown on the diagram in figure 10.

Even with the viewing limitations imposed by the bezel mounting, we feel that it would be possible to recut the Dresden Green diamond to improve its clarity, perhaps even to "flawless," without a signifi-

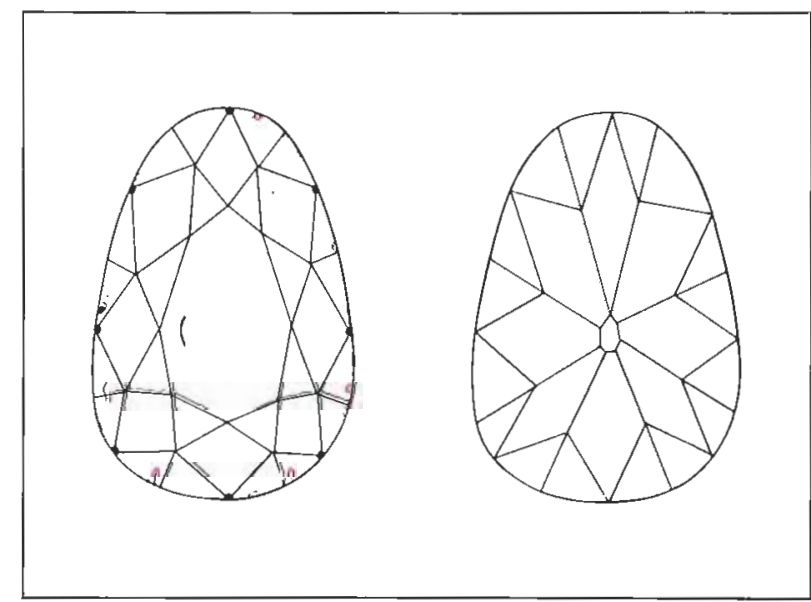

Figure 10. In this plotting diagram of the Dresden Green diamond, the prongs are shown in black; chips, a feather, and a small crystal are plotted in red; the scratch and the radiation stains are plotted in green; and the cavity is plotted in red and green. Artwork by Peter Johnston.

cant weight loss. While we certainly do not suggest that this should ever be done to such a historic diamond, it is a measure of the superior quality of this stone. 
Color. The color of the Dresden Green diamond is its most intriguing feature and was the principal focus of this investigation. This color has been described in the literature by many fanciful terms, with "apple green" perhaps the one most commonly used (Streeter, 1882; Bauer, 1896; Webster, 1947; Smith, 1950; Twining, 1960; Balfour, 1987). Using GIA Colored Stone Grading nomenclature, we visually estimated the color of the diamond to be a medium slightly grayish green. Insofar as the mounting permitted, we determined that the current GIA Gem Trade Laboratory system would grade this historic stone as "Fancy Green."

The ingenuity of the cutter of this stone becomes apparent when one realizes that the Dresden Green shows much more color face up than it exhibits face down. The cutter apparently understood that different proportions are necessary to maximize the face-up color of fancy-color diamonds. He cut the green diamond with a ratio of crown height to pavilion depth that was contrary to what was common practice at that time. London jeweler David Jefferies, in his 1750 treatise on the methods of manufacturing diamonds, stated that the proper proportions were approximately $33 \%$ for the crown and $66 \%$ for the pavilion. The Dresden Green, however, was fashioned with approximately $41 \%$ for the crown and 59\% for the pavilion. Tillander (1988) states that during the early 1700 s, cutting of this quality almost certainly was done in London.

\section{GEMOLOGICAL PROPERTIES}

A thorough investigation was carried out on the Dresden Green diamond to document as many gemological characteristics as possible and to search for any evidence that might prove useful in distinguishing natural and laboratory-irradiated green diamonds. Some of these observations concur with those reported by Bosshart (1989); others reflect our research conducted during and subsequent to the examination.

Color Distribution. Examination of the diamond in darkfield and diffused transmitted illumination revealed no evidence of color zoning. The body color was evenly distributed throughout the gem.

Graining. When the stone was examined with magnification and darkfield illumination, internal planar graining was evident in three different directions (figure 11). The appearance of the colorless, parallel striations was consistent with that often referred to by gemologists as "phantom"

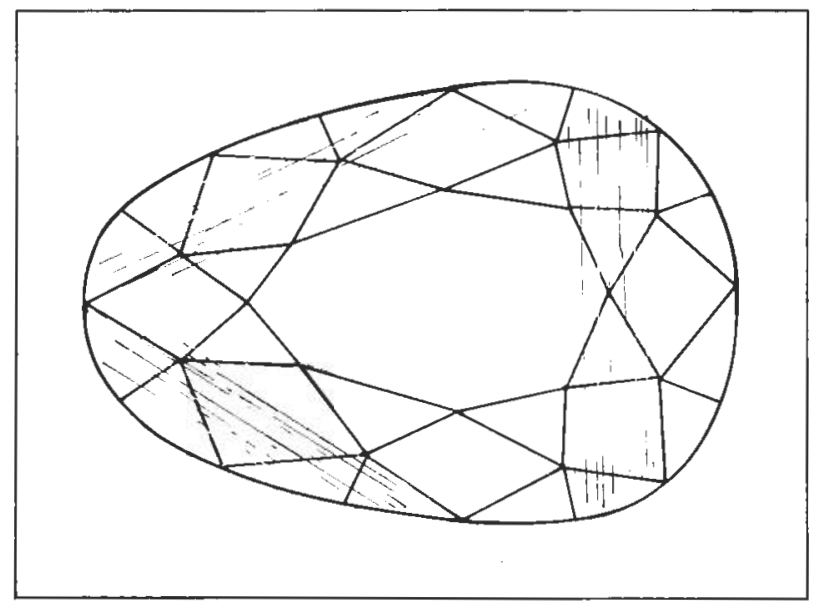

Figure 11. The unusual triangular pattern of graining seen in the Dresden Green indicates that it is a "three-point" diamond. Artwork by Peter fohnston.

graining (Kane, 1982). These growth features, or graining, appeared to be of a triangular octahedral stratified structure. However, as discussed below, this diamond is a type lla, and Orlov (1977) states that "type II diamonds do not show octahedralplane stratification."

The distinctly triangular pattern formed by these three directions of graining is not often seen in faceted diamonds. It suggests that the Dresden Green is a "three point" diamond; that is, the table has been oriented parallel to the direction of a possible octahedral face (for more information, see Watermeyer, 1982).

Strain. Polarized microscopy with the stone held table to culet revealed strong, tightly woven, "cross-hatched" birefringence patterns that are sometimes referred to as "tatami," after the Japanese straw mat of the same name (Orlov, 1977). Both these "tatami" patterns and the linear strain patterns that were also present appeared gray to black. Turning the stone in various directions revealed strong linear and loose cross-hatch strain of a somewhat higher order, with dull, moderately saturated colors of yellow and blue.

Some of the areas of linear strain visible with crossed Polaroids seemed to correlate directly to the colorless graining seen in darkfield illumination through the crown.

Reaction to Ultraviolet Radiation. With a standard GIA GEM short-wave/long-wave ultraviolet lamp used in conjunction with a GIA GEM ultraviolet 
viewing cabinet in ideal conditions of darkness, we observed no fluorescence in the Dresden Green diamond to either long- or short-wave ultraviolet radiation.

We then used a more powerful long-wave ultraviolet radiation unit /VEB Quarzlampen Markkleeberg UA150.1, 220 volt, 140 watt, $365 \mathrm{~nm}$ ). With this extremely strong source, we observed a weak dull green fluorescence. There was no phosphorescence.

Transmission Luminescence. Because some diamonds exhibit a phenomenon known to gemologists as transmission luminescence, we examined the Dresden Green for this characteristic. The diamond was placed, both table down and table up, over the strong light source emanating from the small opening of the nearly closed iris diaphragm over the transmitted light portal of the microscope. The stone showed no transmission luminescence at all, not even the very weak, whitish scattering of light seen in many fancy-color diamonds.

Evidence of Radiation Damage. One of the first things we looked for when examining the Dresden Green with the microscope was the presence of green or brown "radiation stains" (as they are referred to in the gemological literature), which indicate radiation damage to the stone. We fully expected to find some and were not disappointed. Three areas displayed small dark green stains: two at the girdle edge on one side of the diamond and one on an upper girdle facet (figure 12) The last was

Figure 12. At first glance, this appears to be a normal radiation "stain" (evidence of radiation damage) on the surface of an upper girdle facet of the Dresden Green diamond. Photomicrograph by Robert E. Kane; magnified $25 \times$.

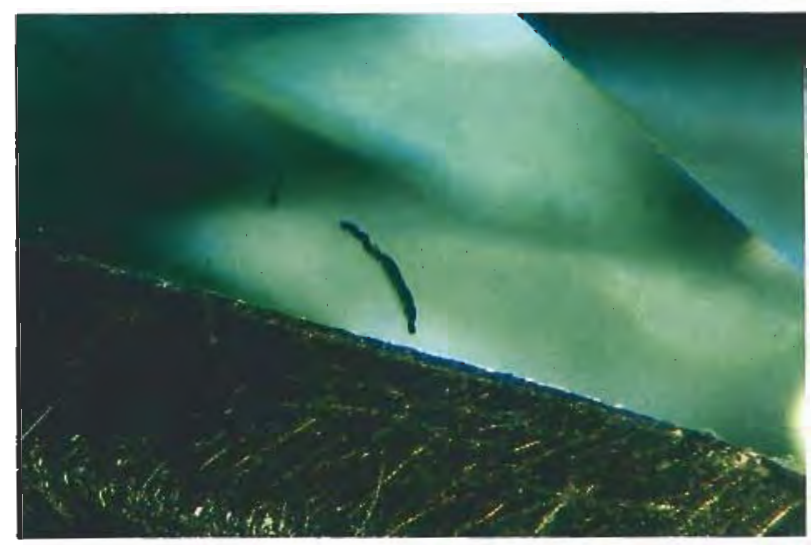

unusual because the stains were coating the walls of a small, narrow cavity that reached the surface by means of a thin fissure (figure 13). This suggests that the diamond was exposed to a radioactive solution that was able to penetrate the cavity through the minute fissure. It is possible that other stains could have been present on the small portion of the girdle obscured by the remaining bezel.

While these stains provide evidence that the Dresden Green originated from a green-skinned piece of rough, they are much too small to account for any of the face-up color of the stone. The Dresden Green diamond is a "body color" green diamond; that is, the color is uniform throughout.

Diamonds with green "skins" or scattered green patches (radiation stains) are common. They are found in varying concentrations in many diamond deposits (Orlov, 1977; Vance et al., 1973). When such diamonds are cut, they generally produce near-colorless stones.

Faceted diamonds with a natural green body color, like the Dresden, are extremely rare. Unlike transparent green surface coats, green body color can be produced by only a few types of ionizing radiations. Alpha and beta particles penetrate diamond to a very shallow depth, on the order of hundredths of a millimeter and a millimeter, respectively (Ashbaugh, 1988), which virtually excludes them from causing the color in the Dresden diamond, although they typically cause the green "skins" or radiation stains. The penetration of ionizing radiation forces carbon atoms out

Figure 13. Upon closer inspection in reflected light, it can be seen that the radiation stain is actually inside a cavity that has only a very narrow opening at the surface. Photomicrograph by Robert E. Kane; magnified $25 \times$.

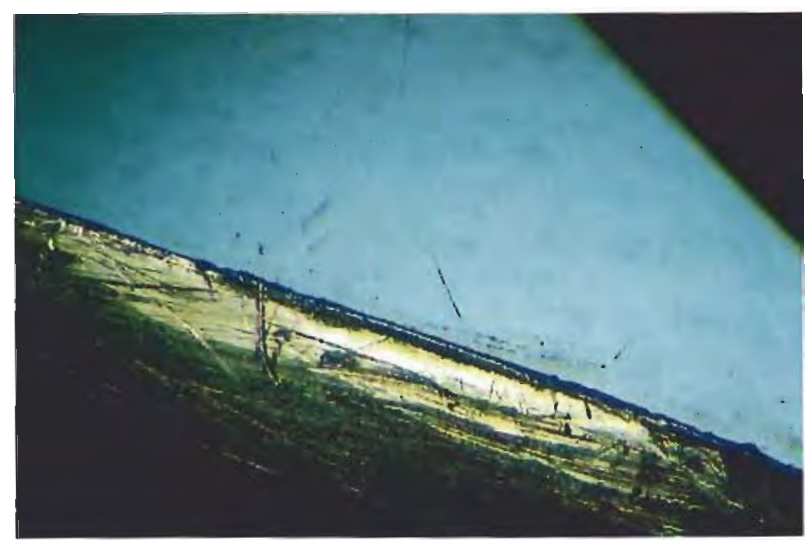


of their positions in the crystal lattice, leaving behind what are known as vacancies. These vacancies produce what is referred to as a GR1 color center, which displays a sharp absorption band at $741 \mathrm{~nm}$ and absorbs light in the red portion of the spectrum, thereby contributing to the green color in a diamond.

The same process occurs with gamma rays and neutrons, but penetration depths are much greater than for alpha and beta particles. As the documented history of the Dresden Green predates the nuclear industry by almost two centuries, naturaloccurring radiation sources are responsible for the color. Nuclides and daughters (decay products) of uranium-238, thorium-232, and potassium-40 are the probable materials, as these produce alpha, beta, and gamma rays. Of these, gamma rays seem the most likely candidate, but there is another possibility. Uraninite, a concentrated uraniumbearing oxide, sometimes undergoes natural spontaneous nuclear fission, which releases neutrons, so that neutrons as well as gamma rays may have damaged the Dresden Green to give the diamond a green body color (G. MacKenzie, pers. comm., 1990).

Nuclear laboratory radiation sources are much more intense than natural sources, and therefore produce in a matter of hours, or even minutes, a coloration in diamond that may require hundreds of millions of years in nature (C. Ashbaugh, pers. comm., 1990). Nuclear reactors generate both gamma rays and fast neutrons.

Small green-to-brown radiation stains /damage) on the surface of diamonds used to be considered a strong indication (but not proof) of natural color (Fryer et al., 1981; Crowningshield, 1985, 1986), since such stains had not been reported to have been produced artificially (Fritsch et al., 1988; Kammerling et al., 1990; Shigley and Fritsch, 1990). However, the possibility now exists that near-colorless and light green or yellow diamonds with these stains may be irradiated to induce or intensify (to light, medium, or dark) a green color. In fact, Kammerling et al. (1990) examined several faceted diamonds with brown radiation stains both before and after irradiation treatment. Even though the originally pale green and near-colorless stones turned dark green with irradiation, there was no change in the appearance of the radiation stains.

Spectra Visible with a Hand-held Type of Spectroscope. We initially examined the visible-light absorption spectrum (400 to $700 \mathrm{~nm}$ ) of the Dresden Green diamond using the GIA GEM Maxilab unit with a Beck prism spectroscope. Close inspection at room temperature revealed no distinct absorption features; only a very weak, broad absorption was visible around $500 \mathrm{~nm}$.

U.V.-VIS Spectra. The U.V.--visible absorption spectrum of the Dresden Green was recorded on a Pye Unicam SP8-100 UV/VIS spectrophotometer, which was supplied and operated by George Bosshart of the SSEF. This examination, performed at close to liquid nitrogen temperature, revealed a well-developed GR (General Radiation) absorption system as well as very weak lines at $495 \mathrm{~nm}$ and $594 \mathrm{~nm}$, the TR 12 line $(470 \mathrm{~nm}), \mathrm{R} 11$ and R 10 lines (310.8 $\mathrm{nm}$ and $393.5 \mathrm{~nm}$, respectively) and a steep absorption edge beginning at approximately 225 $\mathrm{nm}$ (as illustrated in Bosshart, 1989, p. 358). It is interesting to note that the spectrum of the Dresden Green shares many similarities with a dark green diamond that was identified as being artificially irradiated (see figure 14). The presence of a color-zoned culet identified this diamond as being treated (Fritsch and Shigley, 1989).

The steep absorption at $225 \mathrm{~nm}$, the fundamental absorption edge, is observable in type II diamonds, which have fewer crystal defects than their type I counterparts (Clark et al., 1956). The GR series, ranging from GR1 through GR8, is found in all diamonds that have been subjected to radiation damage, with the GR1 at $741 \mathrm{~nm}$ being by far the strongest (Collins, 1982). The TR12 line (TR standing for Type II Radiation) is the strongest in a series of lines that are referred to as TR12 through TR17 (470.1, 468.8 [TR12A], 464.3, 446.5, $444.7,440.2$, and 438.0, respectively). Davies et al. (1981) reported that these lines have only been found in type II diamonds that have been irradiated. The R1 1 (310.8 nm) and R10 (393.5 nm) lines are also produced by radiation damage. The R 11 is reported to be found only in type IIa diamonds (Davies, 1977); the R10 is also known as NDI and can be created in all types of diamonds. It is not usually visible in type Ia diamonds because it is masked by a secondary absorption edge typical of that type (Walker, 1979).

For many years, the presence of a 594-nm line was believed to prove laboratory irradiation in a faceted diamond (see, e.g., Liddicoat, 1989). The line is associated with the annealing of irradiated 
diamonds (Dugdale, 1953; Crowningshield, 1957; Collins, 1982; Guo et al., 1986; Fritsch et al., 1988), so it is normally visible in annealed colors (e.g., yellow, brown, orange, pinkl. It is also occasionally seen in laboratory-treated diamonds that are still green (Kane, 1988; Fritsch et al., 1988). While the $594 \mathrm{~nm}$ line has been reported in a number of uncut natural-color diamonds (Cottrant and Calas, 1981; Guo et al., 1986; Shigley and Fritsch, 1990\}, it has rarely been reported in faceted diamonds that could be proved to be natural. By virtue of its documented 250-year history, the Dresden Green now stands as an undisputable example of such a diamond.

Figure 14. This visible absorption spectrum of a type II green diamond that was identified as being treated by means of characteristic color zoning at the culet, shows many features that are present in the spectrum of the Dresden Green. Courtesy of the GIA Research Department. ...

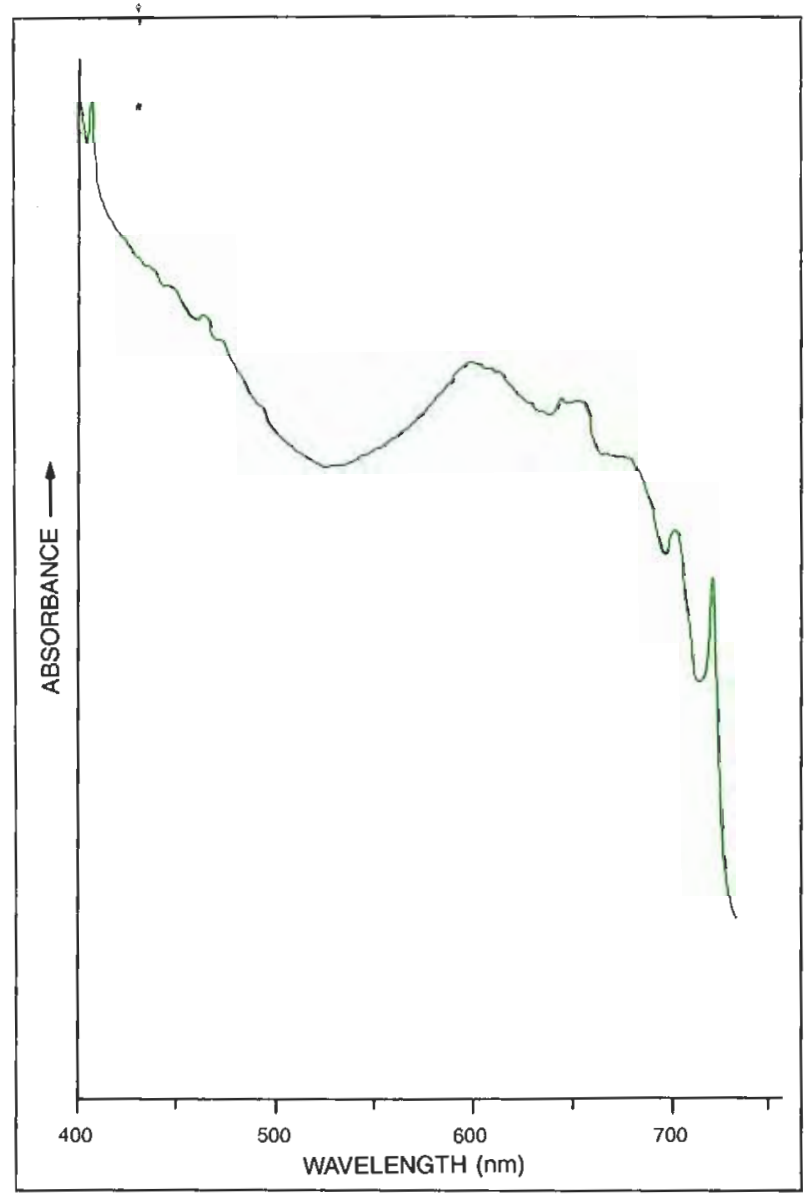

Infrared Spectra. To determine which of the wellrecognized diamond types the Dresden Green belongs to, infrared spectroscopy was used. For a discussion and excellent review of these types (Ia, Ib, IIa, IIb, or a mixture) see, for example, Robertson et al. (1934), Custers (1952), Davies (1977), Clark et al. (1979), Collins (1982), Davies (1984), and Shigley et al. (1986). Very simply stated, type I diamonds have a fairly substantial (up to 3000 ppm, or $0.3 \%$ ) nitrogen content (Shigley et al., 1986). Type Ia diamonds have aggregated nitrogen atoms, while the nitrogen atoms in type Ib diamonds are isolated or "singly substitutional." Type II diamonds have an extremely low nitrogen content, if any (undetectable or barely detectable using IR spectroscopyl; type IIb diamonds contain boron, while type IIa stones do not contain boron in detectable quantities. A diamond can be readily characterized as to type by the way it absorbs or transmits infrared radiation between about 900 and 1400 wavenumbers $\left(\mathrm{cm}^{-1}\right.$; see figure 15$)$.

The infrared spectrum of the Dresden Green diamond (figure 16) was recorded at room temperature on a Carl Zeiss/Jena Specord 75IR infrared spectrophotometer by Dr. K. Herzog and Mrs. R. Lunkwitz of the Technical University of Dresden. The green diamond was mounted in the sample chamber with the infrared beam perpendicular to the table, so that it entered at the table and exited at the culet. The large culet and the depth $\{10.29$ $\mathrm{mm}$ ) of the green diamond allowed for easy set-up and an excellent optical path. As shown in figure 15 , the spectrum is typical of a type IIa diamond, that is, largely free of nitrogen features in the 1400 to 900 wavenumber region.

Type IIa diamonds (of any clarity and color, or absence thereof) are very rare in nature (Field, 1979). Natural diamonds that are of type IIa and have a dominant green color, whether irradiated naturally or in a laboratory, are exceedingly rare. In an ongoing GIA Research project that formally began in 1986, more than 1300 colored diamonds (which were either submitted to the GIA Gem Trade Laboratory for official reports or loaned to GIA for scientific study) have been carefully documented to date. Of these, approximately 300 were predominantly green (some with secondary hues of gray, brown, yellow, blue, etc.), with varying tones and saturation (J. Shigley, pers. comm., 1990). Of these 300 "green" diamonds, only 18 were classified as type IIa, with the remainder being type Ia; none was in the Ib or IIb categories. 


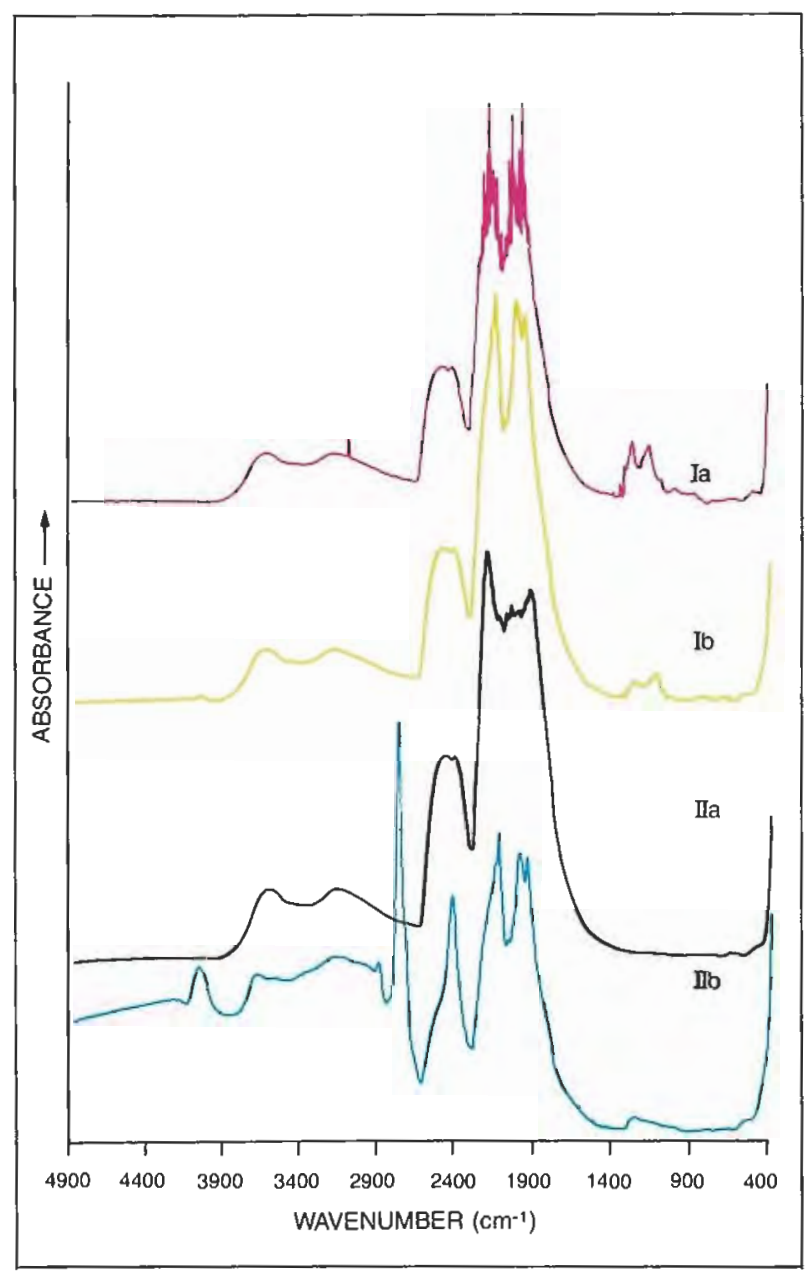

Figure 15. These infrared absorption spectra were recorded with the GIA Research Department's Nicolet 60XS FTIR spectrometer for each of the four basic types of diamond. Each type can be readily characterized by the way it $a b$ sorbs or transmits radiation between about 900 and 1400 wavenumbers $\left(\mathrm{cm}^{-1}\right)$.

Therefore, not only is the famed Dresden Green the largest known natural green diamond, but it is also a very rare type IIa. This was an unexpected discovery, since type Ia diamonds represent as much as $95 \%$ of natural gem diamonds /Collins, 1982).

\section{CONCLUSION}

Natural green body-color diamonds are extremely rare in nature, and there are few documented examples. The Dresden Green falls into this category. The vast majority of natural-color green diamonds are only green on the surface of the rough, with the color produced by surface stains and coatings. These stones are usually no longer

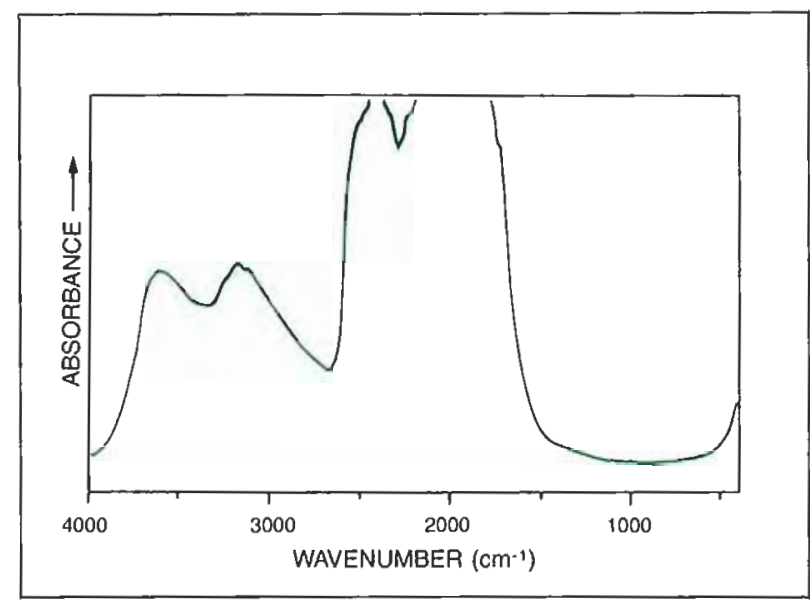

Figure 16. The infrared spectrum of the Dresden Green diamond. Note the similarity of the area between 900 and 1400 wavenumbers with that illustrated in figure 15 for type IIa diamonds. This spectrum was originally recorded in trans mittance; here, it is shown converted to absorbance. Spectrum recorded by Dr. K. Herzog and Mrs. R. Lunkwitz of the Technical University of Dresden.

green when they are cut. The cause of the green surface coloration has been attributed to the diamond being in close proximity to an alpha-particle-emitting source for a very long period of time.

Laboratory-irradiated green diamonds have become increasingly common in the trade. Green color in diamonds has been produced by radium salts since 1904, by cyclotron treatment since 1942, and more recently by high-energy electrons, neutrons, and (less commonly) by gamma rays. Whereas radium and americium salts and cyclotron treatment leave readily identifiable clues radioactivity and what is commonly referred to as the "umbrella" effect, respectively; see Kammerling et al., 1990|, treatment by the more modern methods is extremely difficult to detect in most green diamonds.

Alan Collins stated in 1982 that it would be of considerable help to the understanding of naturally occurring color centers if absorption spectra could be obtained for a natural body-color green diamond. This unique opportunity to examine the Dresden Green provided such information. The documentation of this famous diamond is now complete, with the exception of the precise weight, which may never be known. Our investigation uncovered evidence to support the opinion that the stone was mined in India and cut in London. It was also shown to be a rare type Ila diamond. Most important, perhaps, is the fact that the spectral 
characteristics of this stone overlap those of known treated green diamonds, which indicates that we must continue the search for reliable tests to separate natural from treated green diamonds. It is ironic that a stone with a history that spans more than two and a half centuries should play such a pivotal role in confirming the need for this research.

Acknowledgments: The authors thank Dona Dirlam, Rosemary Tozer, and the others at the Richard $T$. Liddicoat Library and Information Center of GIA for their help in archival research; Holly Baxter, Dr. Barbara Bopp, Dr. John Hummel, and Caio Maia for translations; Dick Agnew and Bob Van den Heuvel for the design and construction of specialized equipment for the investigation; Dr. Peter Tandy and Dr. A. M. Clark of the British Museum of Natural History, for informalion and loan of the model; David Beasley of Goldsmith's Hall, London, for black-and-white reproductions; Herbert Tillander for supplying historical information and making the necessary introductions to gain access to the Green Vaults; George Bosshart of the SSEF for supplying the information on the UV-VIS spectra; Dr. Werner Quellmalz, Dr. Mathe, Mrs. Christine Engemann-Wendt, Dr. U. Arnold, Dr. Klaus Herzog, Mrs. Renate Lunkwitz, Prof. Dr. Walther E. Steger, Dr. Copal, Dr. Tallheim, Dr. Schneider, Mr. Wunsche, and all the other people in Dresden who assisted during the visit; Dr. Karl Schmetzer, Eric Bruton, Michael O'Donoghue, Ian Balfour, Rudolf Dröschel, and Mr. and Mrs. Jerusalem for their help with literary research; Dr. George Rossman, Chuck Ashbaugh, Dr. Jeff Harris, Bob Crowningshield, and Dr. James Shigley for their useful comments and observations; the GIA Research Department for making available their diamond literature database; GIA executives William E. Boyaiian, Richard T. Liddicoal, Courtney A. Walker, Thomas C. Yonelunas, and C. W. Fryer for their support of the Dresden Expedition; and Mary Smith for her expertise and patience in word processing the many drafts of the manuscript.

\section{REFERENCES}

Ashbaugh C.E. (1988) Gemstone irradiation and radioactivity. Gems et Gemology, Vol. 24, No. 4, pp. 196-213.

Balfour I. (1987) Famous Diamonds. William Collins Sons \& Co., London, pp. 74-76.

Bauer M. (1896) Edelsteinkunde. Chr. Herm. Tauchnitz, Leipzig.

Bauer M. (1904) Precious Stones. Charles Griffin and Company, London.

Bauer M. (1932) Edelsteinkunde. K. Schlossmacher, Ed. B. Tauchnitz, Leipzig.

Bosshart G. (1 1989) The Dresden Green. Journal of Gemmology Vol. 21, No. 6, pp. 351-362.

Boutan M.E. (1886) Le Diamant, Imprimerie A. Lauhure, Paris,

Bruton E. \{1978\} Diamonds, 2nd ed. Chilton Book Co., Radnor, PA.

Cattelle W.R. \{1911\} The Diamond. John Lane, The Bodley Head, London.

Clark C.D., Ditchburn R.W., Dyer N.B. (1956) The absorption spectra of natural and irradiated diamonds. Proceedings of the Royal Society, Vol. 234, pp. 363-381.

Clark C.D., Mitchell E.W.J., Parsons B.J. (1979) Colour centres and optical properties. In J. E. Field, Ed., The Properties of Diamond, Academic Press, New York, pp. 23-77.

Collins A.T. (1982) Colour centres in diamond. Journal of Gemmology, Vol. 18, No. 1, pp. 37-75.

Copeland L.L. (1974) Diamonds . . . Famous, Notable and Unique, 1st ed., 2nd rev. printing. Gemological Institute of America, Santa Monica, CA.

Cottrant J., Calas G. (1981) Étude de la coloration de Quelques Diamants du Museum National d'Histoire Naturelle. Revue de Gemmologie a.f.g., Vol. 67, pp. 2-5.

Crowningshield G.R. (1957) Spectroscopic recognition of yellow bombarded diamonds. Gems ↔) Gemology, Vol. 9, No. 4, pp. 99-117.

Crowningshield G.R. (1985) Gem trade lab notes: Diamond with natural internal irradiation stain. Gems $\theta$ Gemology, Vol. 21, No. 4, p. 233.
Crowningshield G.R. (1986) Gem trade lab notes: Natural-color light green diamonds. Gems et) Gemology, Vol. 22, No. 3, pp. $171-172$.

Custers R.M. (1952) Unusual phosphorescence of a diamond Physica, Vol. 18, No. 8-9, pp. 489-496.

Davies G. (1977) The optical properties of diamond. Chemistry and Physics of Carbon, Vol. 13, Marcel Dekker, New York.

Davies G. (1984) Diamond. Adam Hilger, Bristol, Englind.

Davies G., Foy C., O'Donnell K. (1981) The TR12 vibronic band in diamond. Journal of Physics C: Solid State Physics, Vol. 14. pp. 4153-4165.

Dugdale R.A. (1953) The colouring of diamonds by neutron and electron bombardment. British lournal of Applied Physics, Vol. 4, pp. 334-337.

Erbstein I., Erbstein A. (1884) Das Königliche Grüne Gewölbe $Z u$ Dresden. Officin von Wilhelm Baensch, Dresden.

Field J.E. (1979) The Properties of Diamond. Academic Press, London.

Fritsch E., Shigley J., Stockton C., Koivula J. (1988) Detection of treatment in two unusual green diamonds. Gems \&) Gemology, Vol. 24, No. 3, pp. 165-168.

Fritsch E, Shigley J.E. (1989) Contribution to the identification of treated colored diamonds: Diamonds with peculiar color-zoned pavilions. Gems et) Gemology, Vol. 25, No. 2, pp. 95-101

Fryer C.W., Crowningshield G.R., Hurwit K.N., Kane R.E. (1981) Gem trade lab notes: Green diamonds. Gems et Gemology, Vol. 17, No. 4, p. 227.

Führer durch die Königlichen Sammlungen zu Dresden (1918). Albanussche Buchdruckerei, Dresden.

Gaal R.A.P. (1977) The Diamond Dictionary, 2nd ed. Gemological Institute of America, Santa Monica, CA.

Gruner L. (1862) The Green Vaults, Dresden. C. C. Meinhold and Sons, Dresden.

Guo J., Chen F., Cai X., Deng H. (1990) Spectroscopic study of natural diamonds in China. Chinese Journal of Geochemistry, Vol. 9, No. 2, pp. 161-168. 
Harris J.W., Hawthorne J.B., Oosterveld M.M. (1979) Regional and local variations in the characteristics of diamonds from southern African kimberlites. In F. R. Boyd and H. O. A. Meyer, Eds., Diatremes and Diamonds: Their Geology, Petrology and Geochemistry, Washington, DC.

Hein M. (1914) Briefe Friedrichs des Grossen. Hobbing, Berlin

Holzhausen W. (1966) Prachtgefässe, Geschmeide, Kabinet tstücke, Goldschmiedekunst in Dresden. Tübingen, 1966.

Inventory Book of the Grünes Gewölbe (Green Vaults) No. 16 (1733). Grünes Gewölbe, Dresden.

Jeffries D. (1750) A Treatise on Diamonds and Pearls. C. and J. Ackers, London.

Kammerling R., Koivula I., Kane R. (1990) Gemstone enhancement and its detection in the 1980s. Gems e) Gemology, Vol. 26, No. 1, pp. 32-49.

Kane R.E. (1988) Gem trade lab notes: Treated green diamonds. Gems $\Leftrightarrow$ Gemology, Vol. 24, No. 3, pp.170-171.

Kane R.E. (1982) Graining in diamond. In D. M. Eash, Ed. International Gemological Symposium Proceedings 1982, Gemological Institute of America, Santa Monica, CA, pp. 219-235.

Krashes L. (1988) Harry Winston, The Ultimate leweler. Harry Winston, New York, and the Gemological Institute of America, Santa Monica, CA.

Lenzen G. (1970) The History of Diamond Production and the Diamond Trade. Praeger Publishers, New York.

Liddicoat R.T. (1989) Handbook of Gem Identification, 12th ed., 2nd rev. printing. Gemological Institute of America, Santa Monica, CA.

Menzhausen J. (1968) The Green Vaults. Edition Leipzig, Leipsig, Germany.

Menzhausen I. (1986) The Green Vaults: An Introduction, 5th ed. Staatliche Kunstsammlungen Dresden, Dresden.

Meyer H.O.A., Milledge H.J., Nave E. (1965) Natural irradiation damage in lvory Coast diamonds. Nature, Vol. 206, p. 392

Orlov Y.L. (1977) The Mineralogy of the Diamond. John Wiley \& Sons, New York.

Raal F.A. (1969) A study of some gold mine diamonds. American Mineralogist, Vol. 54, No. 1-2, pp. 292-296.

Reis E. (1959) Os Grandes Diamantes Brasileiros. Divisāo de Geologia e Mineralogia, Rio de Janeiro.

Robertson R., Fox J.J., Martin A.E. (1934) Two types of diamond.
Philosophical Transactions, Royal Society of London, Vol A232, pp. 463-535.

Rösch S., Krümbhaar W. (1926) Die Diamanten des Grünes Gewölbe in Dresden. Deutsche Goldschmiede-Zeitung, No. 11, pp. 114-124.

Rösch S. (1957) Das Grünes Gewölbe in Dresden. Zeitschrift der Deutschen Gesellschaft für Edelsteinkunde, pp. $79-84$.

Shigley J.E., Fritsch E. (1990) Optical properties of some greenish blue to green diamonds. Diamond Optics $I I I$ Conference Proceedings, Vol. 1325, pp. 315-324.

Shigley J.E., Fritsch E., Stockton C.M., Koivula J.1., Fryer C.W. Kane R.E. (1.986) The gemological properties of the Sumitomo gem-quality synthetic yellow diamonds. Gems 4$)$ Gemology, Vol. 22, No. 4, pp. 192-208.

Smith G.F.H. (1950) Gemstones, 11 th ed. Methuen \& Co., London.

Spencer C.J. (1971) A Key to Precious Stones, 3rd ed. Emerson Books, New York.

Sponsel J.L. (1915) Führer durch das Königlichen Grünes Gewölbe zu Dresden. Buchdruckerei der Wilhelm und Bertha $V$. Baensch Stiftung, Dresden.

Streeter E.W. (1882) The Great Diamonds of the World. George Bell and Sons, London.

Tillander H. (1988) Golden fleece diamonds. Unpublished manuscript

Twining L. (1960) A History of the Crown lewels of Europe. B. T. Batsford, London.

Vance E.R., Harris J.W., Milledge H.J. (1973) Possible origins of alpha-damage in diamonds from kimberlite and alluvial Sources. Mineralogical Magazine, Vol. 39, pp. 349-360.

Walker J. (1979) Optical absorption and luminescence in diamond, Reports on Progress in Physics, Vol. 42, pp. $1606-1659$.

Watermeyer B. (1982) Diamond Cutting, 2nd ed. Centaur Publishers, Johannesburg, South Africa.

Von Watzdorf E. (1962) Johann Melchior Dinglinger, Der Gold schmied des Deutschen Barock. Gebr. Mann Verlag, Berlin.

Webster R. (1947) The Gemmologists' Compendium, 2nd ed. N.A.G. Press, London.

\section{WEAR THE SYMBOL OF EXCELLENCE AND PROFESSIONALISM}

\section{The GIA Class Ring The Mark of Achievement}

You're proud of your GIA education and the diploma that you earned. Now you can show your pride by wearing this symbol of excellence and professionalism ... the GIA class ring.

Superbly crafted in $14 \mathrm{~K}$ or $18 \mathrm{~K}$ yellow gold with an antique finish, each ring is topped with the GIA crest and engraved with your year of graduation. Styled in a distinctive octagonal shape, the ring comes in men's and women's sizes. This offer is exchusive to graduates of GIA's diploma programs.

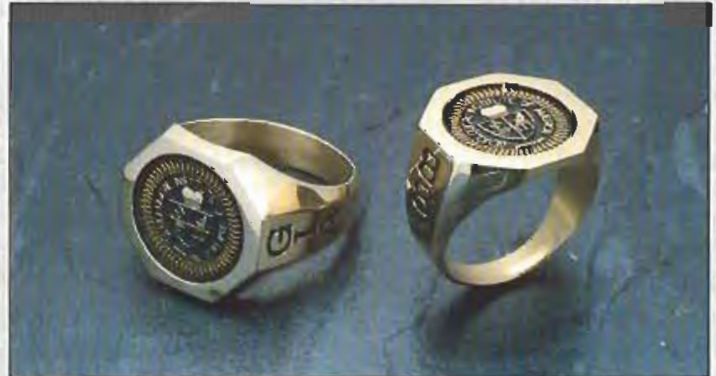

For more information or to place an order, call the GIA Bookstore, Nationwide TOLL-FREE (800) 421.7250, ext. 282 or (213) 829-2991, ext. 282 